\title{
RELAÇÕES ENTRE MEDIAÇÃO E ORGANIZAÇÃO DA INFORMAÇÃO: ESTUDO APLICADO NO SISTEMA DE BIBLIOTECAS DA UNIVERSIDADE FEDERAL DO CEARÁ
}

\author{
RELATIONSHIP BETWEEN MEDIATION AND \\ INFORMATION ORGANIZATION: APPLIED STUDY IN \\ LIBRARY SYSTEM OF THE FEDERAL UNIVERSITY OF \\ CEARÁ
}

Ana Rafaela Sales de Araújoa

Jonathas Luiz Carvalho Silvab

\begin{abstract}
RESUMO
Introdução: Discute perspectivas relacionais entre Mediação e Organização da Informação sob uma percepção plural e integrativa destes campos de pesquisa na biblioteca universitária. Objetivo: Investigar as relações entre mediação e Organização da Informação a partir das percepções dos bibliotecários da Universidade Federal do Ceará. Metodologia: A metodologia constitui-se de pesquisa descritiva-exploratória, revisão bibliográfica, documental, de natureza qualitativa, além do uso de questionário e da análise de conteúdo. Resultados: O questionário foi respondido por 33 bibliotecários com o seguinte perfil: grande parte atua mais fortemente com os processos de catalogação; $76 \%$ demonstram satisfação com o Sistema Pergamum no âmbito da Organização e Representação da Informação; 82\% apresentam-se satisfeitos com a atuação do Sistema de Bibliotecas da UFC no âmbito da Organização da Informação; 88\% responderam quais os processos de catalogação, indexação, sistemas de classificação são utilizados no SB/UFC, em conformidade com as políticas existentes, independente de atuarem ou não nesses processos; em relação ao conhecimento sobre mediação, $66,7 \%$ utilizam leituras próprias e leituras recomendadas; $66 \%$ informam os eventos como forma de incentivo e parceria para 0 desenvolvimento de ações mediadoras; $90,9 \%$ identificam atividades mais voltadas à mediação pedagógica, ou seja, serviço de referência e educação de usuários como elementos de atuação no âmbito da mediação da informação; com relação às práticas de mediação que o sistema de bibliotecas da UFC desenvolve, têm-se como destaque as ações mediadoras consideradas tradicionais: catalogação $(51,5 \%)$; indexação (48,5\%); classificação (48,5\%). Conclusões: conclui-se que a mediação na
\end{abstract}

a Mestra em Biblioteconomia pela Universidade Federal do Cariri (UFCA). Bibliotecária Documentalista da Universidade Federal do Ceará (UFC).E-mail: anarafaela@alu.ufc.br

b Doutor em Ciência da Informação pela Universidade Federal da Bahia (UFBA). Professor do Curso de Graduação e do Mestrado Profissional em Biblioteconomia da Universidade Federal do Cariri (UFCA).E-mail: jonathascarvalhos@yahoo.com.br 
Organização da Informação pode ser pensada a partir dos seguintes aspectos: Representação Descritiva e Temática da Informação; Sinalização; Política de Desenvolvimento de Coleções; Serviços; Produtos; Preservação da memória; Uso de recursos virtuais. Inclusive, a união dos aspectos elencados expressa uma percepção mais holística para repensar a mediação a partir da Organização da Informação.

Descritores: Mediação da informação. Mediação técnica da informação. Organização da informação. Bibliotecas universitárias. Universidade Federal do Ceará.

\section{INTRODUÇÃO}

A mediação é uma temática estudada por diversas áreas, por exemplo: Direito, Educação, Comunicação, Biblioteconomia, Ciência da Informação. Esses âmbitos do conhecimento possuem diferentes concepções sobre 0 conceito de mediação, algumas associadas e interseccionadas, tornando a mediação multidisciplinar e plural, realizada sob várias nomenclaturas: mediação jurídica, mediação cultural, mediação da informação, dentre outras.

Dentre as concepções apreendidas, este artigo pauta-se na mediação da informação, com estudos conceituais recentes na área de Ciência da informação, além de pesquisas e aplicações profissionais no tocante à Biblioteconomia.

A mediação da informação é vislumbrada como fator condicionante para a realização de todas as atividades do bibliotecário, perpassando, inclusive, pelos processos de Organização da Informação, ou seja, o tratamento descritivo e temático da informação.

Neste artigo, pretende-se abrir um leque de possibilidades no que tange às novas concepções da mediação no âmbito da Organização da Informação, evidenciando a pluralidade e a vitalidade deste campo de pesquisa na ambiência da biblioteca universitária.

A partir destas breves considerações, o presente estudo possui o intuito de buscar respostas ao seguinte problema: Quais as relações entre Mediação e Organização da Informação a partir das percepções dos bibliotecários da Universidade Federal do Ceará?

Essa problemática surgiu da inquietude provocada a partir da participação em um evento de cunho profissional, promovido pelo Sistema de Bibliotecas da 
Universidade Federal do Ceará (SB/UFC), em 2016, durante o curso "Mediação da Informação e Educação de Usuários em Bibliotecas Universitárias" e, que gerou algumas análises introdutórias, a saber: as múltiplas possibilidades da Organização da Informação como fenômeno de mediação pareciam pouco compreendidas e vislumbradas pelos bibliotecários; a ênfase e a valorização dos profissionais acerca das atividades de mediação explícita/pedagógica, presentes na educação de usuários, serviço de referência, disseminação seletiva da informação etc.

Diante disso, é pertinente que o campo da Ciência da Informação busque aprimorar as concepções sobre as contribuições da mediação no processo de Organização da Informação. Por conseguinte, devido à carência de pesquisas e preocupações geradas em torno desta temática, é que se justifica a realização deste artigo, com a perspectiva de colaborar com os que surgirem posteriormente, além de suscitar novas percepções sobre este mesmo objeto.

Face ao exposto, este artigo é fruto de um recorte da dissertação intitulada: "Mediação no âmbito da Organização da Informação: proposta de um Programa de atuação para o Sistema de Bibliotecas da Universidade Federal do Ceará".

Desse modo, possui como objetivo investigar as relações entre mediação e Organização da Informação a partir das percepções dos bibliotecários da Universidade Federal do Ceará.

Na segunda seção abordam-se as concepções relacionais entre mediação e Organização da Informação no contexto da biblioteca universitária. A terceira seção trata da metodologia, que se constitui de uma pesquisa exploratóriodescritiva; de natureza qualitativa; documental; revisão bibliográfica (análise dos fatos disponíveis na literatura) para discorrer sobre as relações entre mediação e Organização da Informação nos processos propostos a seguir: catalogação; classificação; indexação; sinalização da biblioteca; política de desenvolvimento de coleções; serviços; produtos; preservação da memória e uso de recursos virtuais.

Por conseguinte, a quarta seção compreende a análise de dados do questionário destinados aos bibliotecários. Por fim, a quinta seção apresenta as considerações finais da pesquisa pautadas na perspectiva global acerca dos resultados obtidos mediante análise construída, o problema de pesquisa 
delineado e o atendimento dos objetivos.

\section{CONCEPÇÕES RELACIONAIS ENTRE MEDIAÇÃO E ORGANIZAÇÃO DA INFORMAÇÃO NA BIBLIOTECA UNIVERSITÁRIA}

Sob a ótica da mediação da informação, a biblioteca universitária reconfigurase como um ambiente de informação, educação, formação, cultura, leitura e, não como um mero espaço de coleções de livros. Neste entendimento, a biblioteca ganha dinamicidade e vivacidade, tanto em seus espaços como em seus serviços.

A função mediadora da biblioteca universitária reside na satisfação das necessidades de informação da comunidade e, de forma mais ampla, em fazer parte do cotidiano do usuário, estimulando o diálogo, a construção e a apropriação da informação (SILVA; SILVA, 2012).

Silva (2015, p. 103) conceitua a mediação da informação como:

[...] um conjunto de práticas construtivas de intervenções e interferências regidas por intencionalidades, normas/regras, correntes teórico-ideológicas e crenças concebidas pelo profissional da informação em interação com os usuários no âmbito de suas realidades cotidianas e experienciais, indicando procedimentos singulares, coletivos e/ou plurais de acesso e uso da informação, estimulando a apreensão e apropriação para satisfação de necessidades de informação.

No que diz respeito aos tipos de mediação da informação, Silva (2015) trabalha com três propostas, a saber:

a) mediação técnica da informação ${ }^{3}$ ações de Organização da Informação realizadas pelo profissional da informação com o intuito de estimular o uso da informação, tanto virtualmente como presencialmente;

b) mediação pedagógica da informação: ações que envolvem estudos de usuários, de comunidades, uso do acervo, avaliação da satisfação dos serviços promovidos pelo centro de informação com o intuito de buscar uma aproximação com a comunidade, assim como promover a

\footnotetext{
${ }^{3}$ Neste artigo, adota-se a concepção de mediação técnica da informação, elaborada por Silva (2015), devido à perspectiva de pontos de confluência entre as demais tipologias de mediação da informação pedagógica e institucional, bem como pela concepção holística da biblioteca e do fazer bibliotecário, presente na tipicidade preconizada.
} 
autonomia e a apropriação da informação pelo usuário;

c) mediação institucional da informação: relaciona-se com procedimentos de como o profissional da informação captará recursos, seja dentro ou fora da instituição a qual o centro de informação está inserido a fim de concretizar suas ações e interferências e, assim, promovendo sua sustentabilidade.

Evidencia-se a ideia de que o usuário se faz presente nos três tipos de mediação da informação depreendidos, já que a mediação é realizada para e com o usuário (SILVA; SILVA, 2012).

Em resumo, tem-se a seguir as perspectivas de mediação no âmbito da Organização da Informação, compiladas na pesquisa de mestrado.

\section{Figura 1 - Perspectivas da mediação no âmbito da Organização da Informação}

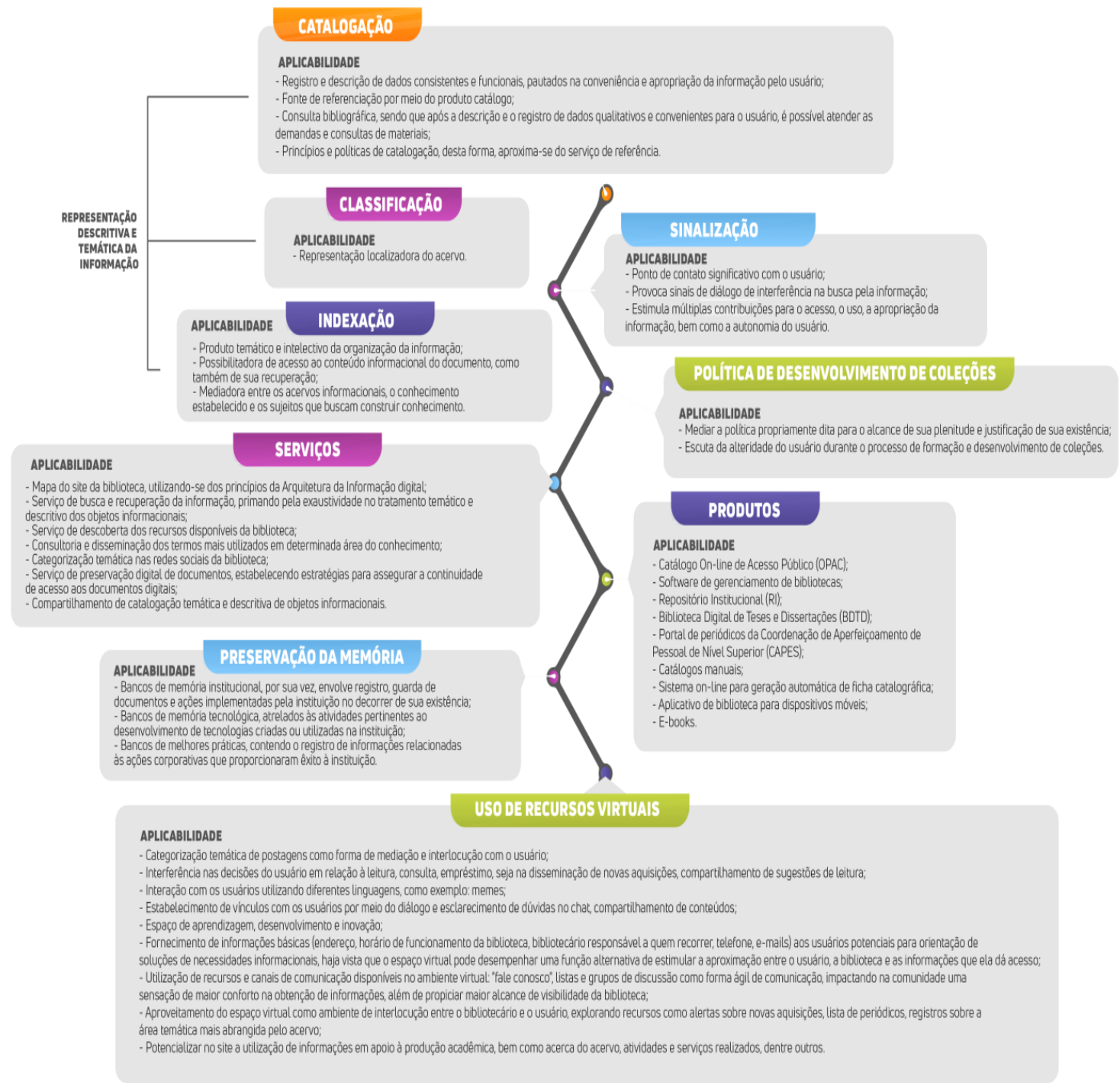

Inf. Inf., Londrina, v. 25, n. 2, p. 400 - 427, abr./jun. 2020. 
Ana Rafaela Sales de Araújo, Jonathas Luiz Carvalho Silva

Relações entre Mediação e Organização da Informação: estudo aplicado no Sistema de Bibliotecas da Universidade Federal do Ceará

Fonte: Adaptado de Gomes e Santos (2009); Molina (2010); Silva e Silva (2012); Silva (2016); Redigolo e Silva (2017); Santos Neto e Almeida Júnior (2017).

Em seguida, faz-se menção a todas as seções atinentes à estrutura organizacional do Sistema de Bibliotecas da Universidade Federal do Ceará, às possíveis ações mediadoras no âmbito da Organização da Informação e suas relações diretas e indiretas entre os setores da Biblioteca Universitária (BU), conforme a figura abaixo.

\section{Figura 2 - Ações mediadoras no âmbito da Organização da Informação e suas relações entre os setores da biblioteca universitária}

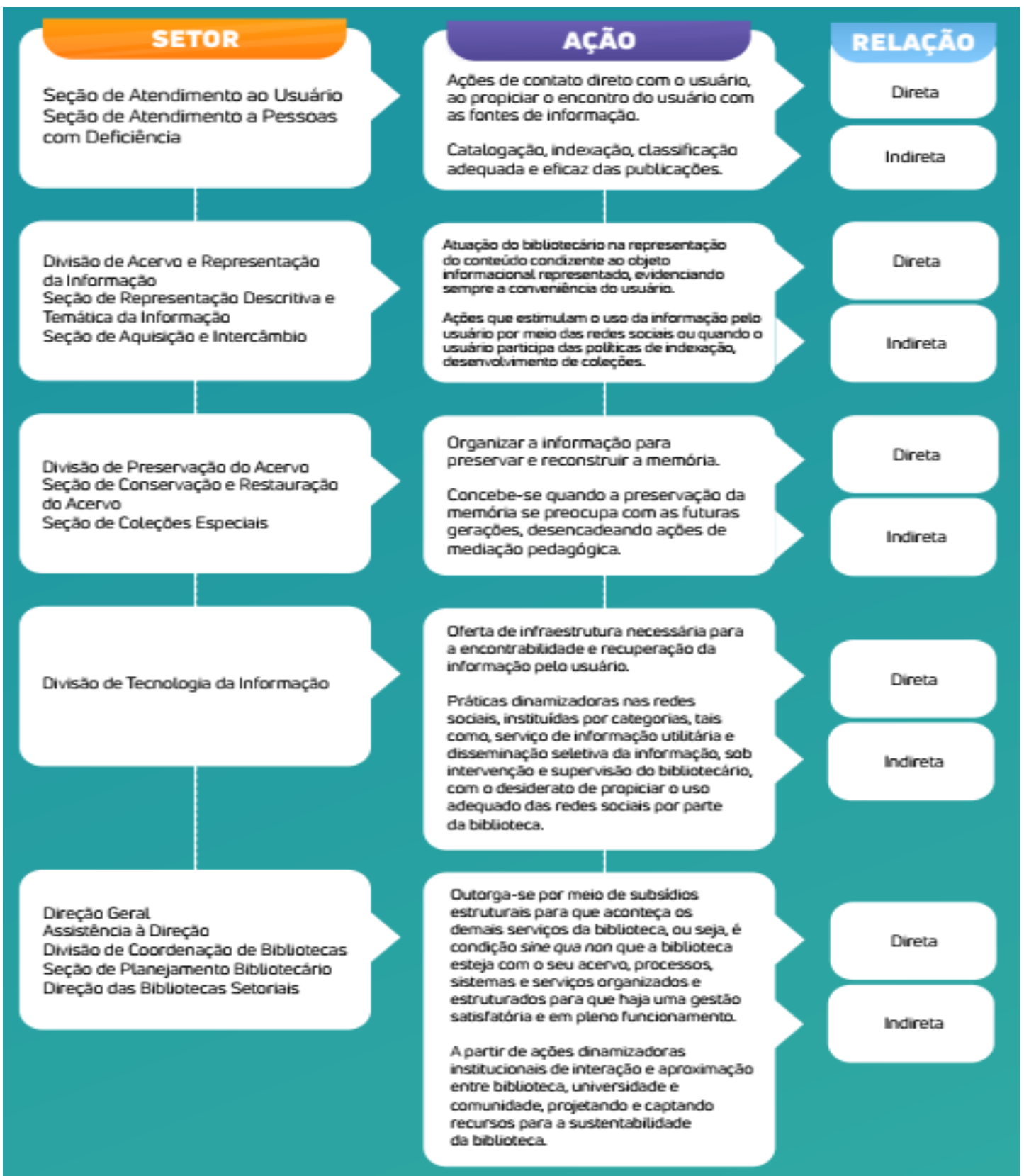

Inf. Inf., Londrina, v. 25, n. 2, p. 400 - 427, abr./jun. 2020. 
Fonte: Adaptado de Ortega y Gasset (2006); Gomes e Santos (2009); Farias (2015); Silva (2016); Fernandes e De Souza (2017); Galeffi et al. (2018).

Vale ressaltar que todos os setores da BU se relacionam de forma direta e indireta com a Organização da Informação, portanto, o que determina o tipo de relação é o intuito da ação realizada.

Exemplificam-se ainda que brevemente, interpretações das ações mediadoras propostas. No que diz respeito ao setor de referência, presente nas bibliotecas setoriais da UFC, denominados atendimento ao usuário e atendimento a pessoas com deficiência, estes se relacionam indiretamente à prática de Organização da Informação, na medida em que os objetos informacionais são catalogados, indexados, classificados adequadamente e eficazmente; dessa forma, o bibliotecário de referência propicia o encontro do usuário com as fontes de informação, face ao exposto por Farias (2015); Fernandes e De Souza (2017).

Em síntese, as ações mediadoras propostas na Figura 2 demonstram uma característica crucial da mediação técnica: a de que é possível pensar a mediação técnica da informação a partir de ações que possuem relações diretas e indiretas com os usuários, diferente da ideia de mediação implícita da informação, proposta por Almeida Júnior (2009). Por isso, justifica-se o uso da tipologia da mediação técnica da informação neste artigo.

\section{METODOLOGIA}

Em relação aos procedimentos metodológicos evidencia-se que a pesquisa é de natureza qualitativa, caracterizada quanto aos seus objetivos como exploratório-descritiva visando investigar as relações entre mediação e Organização da Informação a partir das percepções dos bibliotecários da UFC.

O campo de pesquisa é composto por 19 bibliotecas que integram o Sistema de Bibliotecas da UFC e os sujeitos da pesquisa são os bibliotecários integrantes do referido sistema.

Quanto aos meios técnicos da investigação, aplica-se a revisão bibliográfica, documental (site da UFC e do Sistema de Bibliotecas) para 
discorrer sobre as relações entre mediação e organização da informação nos seguintes processos propostos: catalogação; classificação; indexação; sinalização da biblioteca; política de desenvolvimento de coleções; serviços; produtos; preservação da memória e uso de recursos virtuais.

Para a coleta de dados fez-se uso do questionário com perguntas fechadas; abertas; semiabertas (múltipla escolha com possibilidade de comentários; de escalas de avaliação com quatro a cinco alternativas de resposta e/ou pontos), com o total de 10 perguntas.

Como técnica de análise dos dados coletados, optou-se pela análise de conteúdo com dez categorias estabelecidas a priori: Catalogação, Classificação, Indexação (Representação Descritiva e Temática da Informação); Sinalização; Política de desenvolvimento de coleções; Serviços; Produtos; Preservação da memória; Uso de recursos virtuais; Outros.

Doravante, os sujeitos da amostra foram esquematizados conforme o tamanho da população/universo da pesquisa: 33 bibliotecários de 70 . Convém mencionar que a divulgação do questionário foi realizada presencialmente, por e-mail e enviada para os 70 bibliotecários do SB/UFC, a partir disso, culminou com a obtenção de 33 bibliotecários respondentes.

\section{ANÁLISE DO QUESTIONÁRIO DESTINADO AOS BIBLIOTECÁRIOS}

A apresentação e discussão dos resultados foram realizadas a partir das dez categorias de análise das respostas do questionário destinado aos bibliotecários do SB/UFC, conforme a figura abaixo.

Figura 3 - Categorias a priori para o uso da análise de conteúdo 
Ana Rafaela Sales de Araújo, Jonathas Luiz Carvalho Silva

Relações entre Mediação e Organização da Informação: estudo aplicado no Sistema de Bibliotecas da Universidade Federal do Ceará
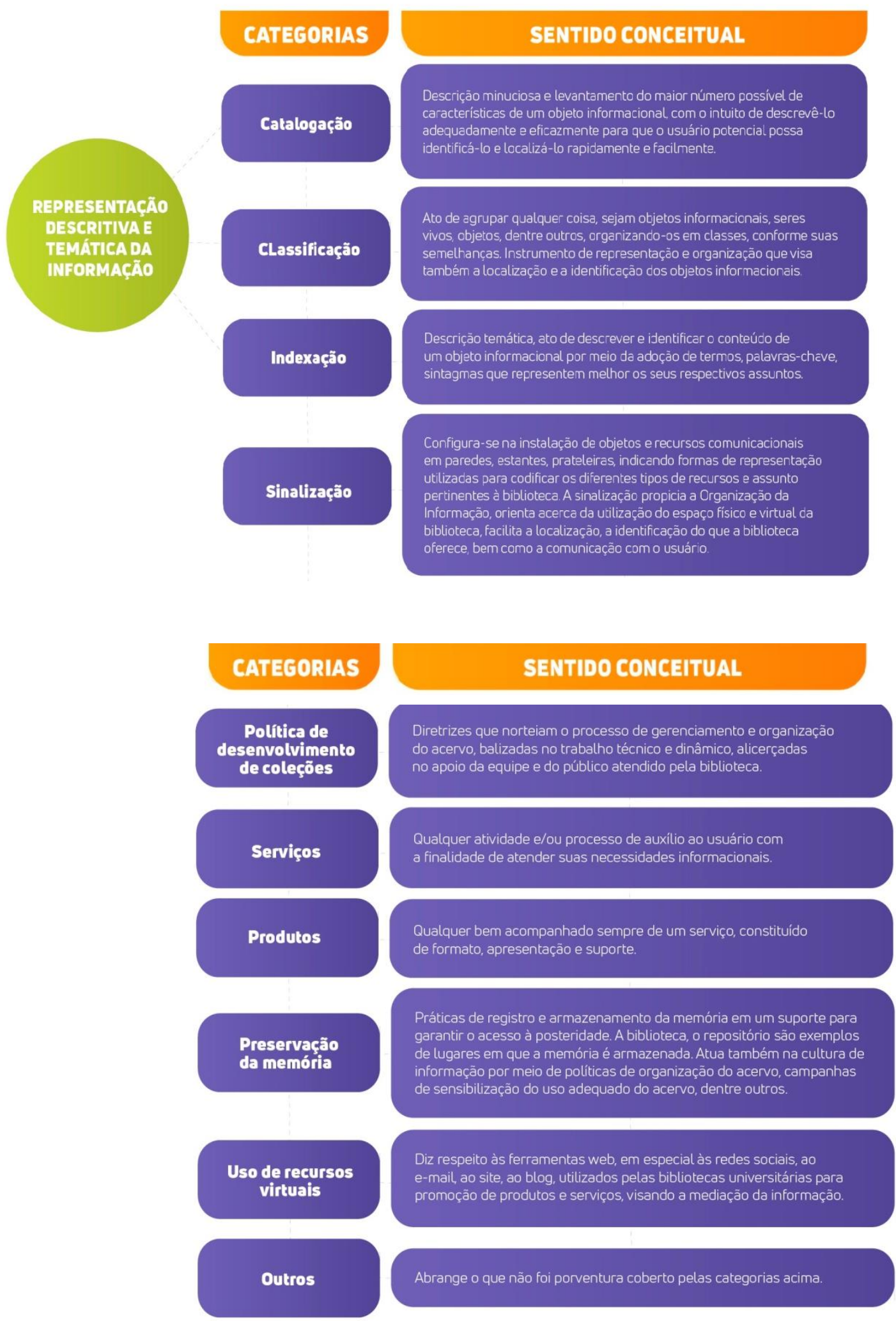

Fonte: Elaborado pela autora.

Convém enfatizar que a categoria "Outros" contempla o que porventura 
não foi tratado nas demais categorias elencadas no quadro, sob a finalidade de evitar a evasão de sentidos na pesquisa. Destaca-se também que o ponto central desta pesquisa é a mediação técnica no âmbito da Organização da Informação, visto que as oito temáticas de análise se apresentam imbricadas ao longo da discussão dos resultados.

Com relação ao grupo de bibliotecários que respondeu ao questionário, houve uma porcentagem expressiva de respostas de $47 \%$, ou seja, 33 respondentes em uma população de 70 bibliotecários.

Concernente aos questionamentos de caráter específico, $15 \%$, ou seja, B10, B14, B15, B16 e B37 compreenderam o primeiro questionamento e atuam mais fortemente com os processos de catalogação, provavelmente devido ao entendimento de que sua atuação basilar perpassa por ela, conforme explicitado no Quadro 1.

Convém destacar que no momento do pré-teste não houve essa dificuldade. Salienta-se também, por oportuno, que a primeira questão apoia-se na categoria "Representação Descritiva e Temática da Informação".

\section{Quadro 1 - Elementos de maior atuação nos processos de Organização e Representação da Informação na Biblioteca Universitária}

\begin{tabular}{|l|c|c|c|c|c|}
\hline \multirow{2}{*}{ Elementos } & \multicolumn{5}{c|}{ Sujeitos da pesquisa } \\
\cline { 2 - 6 } & B10 & B14 & B15 & B16 & B37 \\
\hline Catalogação & $1^{\mathrm{a}}$ & $2^{\mathrm{a}}$ & $2^{\mathrm{a}}$ & $1^{\mathrm{a}}$ & $1^{\mathrm{a}}$ \\
\hline Classificação & $2^{\mathrm{a}}$ & $3^{\mathrm{a}}$ & $1^{\mathrm{a}}$ & $2^{\mathrm{a}}$ & $3^{\mathrm{a}}$ \\
\hline Indexação & $3^{\mathrm{a}}$ & $1^{\mathrm{a}}$ & $3^{\mathrm{a}}$ & $3^{\mathrm{a}}$ & $2^{\mathrm{a}}$ \\
\hline Vocabulário controlado/tesauro & $4^{\mathrm{a}}$ & $4^{\mathrm{a}}$ & $4^{\mathrm{a}}$ & $4^{\mathrm{a}}$ & $4^{\mathrm{a}}$ \\
\hline
\end{tabular}

Fonte: Dados da pesquisa (2018).

Posteriormente, a segunda indagação evoca três categorias: "Representação Descritiva e Temática da Informação"; "Produto"; "Recursos Virtuais", mas a categoria protagonista que norteia é a primeira, devido à utilização do termo Organização e Representação da Informação associados inexoravelmente aos processos de classificação, catalogação e indexação.

Além disso, a segunda e a terceira questão utiliza a escala com opções de 1 a 5 , sendo que a 1 representa muito insatisfatória, e a 5 muito satisfatória. 
Ademais, as avaliações foram transformadas em gráficos para melhor visualização.

A partir do exposto no Gráfico 1 (segundo questionamento), destaca-se que $76 \%$ dos respondentes demonstram satisfação com o Sistema Pergamum no âmbito da Organização e Representação da Informação. Portanto, pode-se denotar que o público pesquisado considera o Pergamum um ótimo software de gerenciamento de bibliotecas no âmbito em questão. Apenas 6\% apresentamse muito insatisfeitos, seguido de $3 \%$ insatisfeitos e indiferentes, respectivamente.

\section{Gráfico 1 - Pergamum como sistema para a Organização e Representação da Informação}
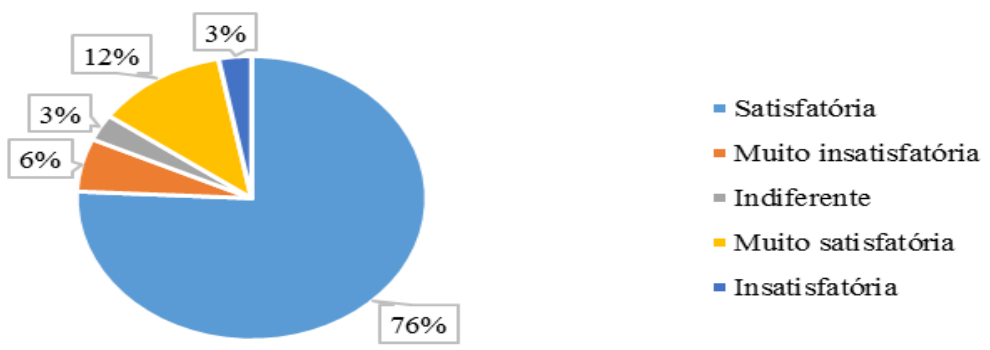

Fonte: Dados da pesquisa (2018).

Neste sentido, é possível elencar em que aspectos essa satisfação ocorre, sobretudo no que tange aos seguintes módulos do sistema Pergamum Web, versão 9.0:

a) catalogação e seus desdobramentos - cadastro, autoridade, conferência de dados, cadastro exemplar, periódicos/encadernação, intercâmbio, exportação de dados, fornecedor, etiquetas, transferência;

b) relatórios e estatísticas - circulação e conferência de materiais, consultas, dados de aquisição, levantamentos bibliográficos, usuários, diversos;

c) consulta ao acervo.

No tocante ao terceiro questionamento, $82 \%$ do público estudado apresenta-se satisfeito com a atuação do Sistema de Bibliotecas da UFC no 
âmbito da Organização da Informação, conforme o Gráfico 2.

Dessa forma, é importante introduzir sobre quais subsídios essa satisfação ocorre, especificamente nas atividades de representação descritiva e temática; aquisição de material bibliográfico por meio de compra ou doação; análise de plano de ensino dos cursos, em consonância com a avaliação do Ministério da Educação; controle do acervo e prestação de contas por meio do inventário do acervo; intercâmbio de publicações; gestão de coleções especiais; serviços de encadernação e higienização do acervo; questões relacionadas ao repositório institucional; relatório e planos de trabalho; publicação de conteúdos nas mídias sociais das bibliotecas; comissões especializadas de estudo (acervo, catalogação, serviços).

A referida questão integra todas as categorias: Representação Descritiva e Temática da Informação; Sinalização; Política de Desenvolvimento de Coleções; Serviços e Produtos; Preservação da Memória; Uso de Recursos Virtuais, especialmente a de Representação Descritiva e Temática da Informação.

\section{Gráfico 2 - Atuação do SB/UFC no âmbito da Organização da Informação}

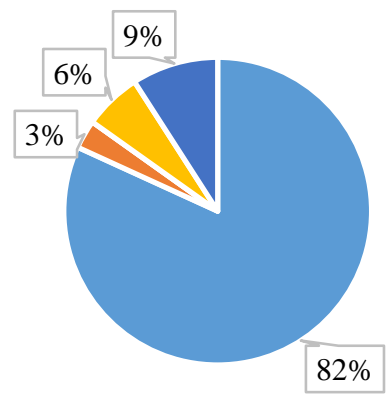

$$
\begin{aligned}
& \text { - Satisfatória } \\
& \text { - Muito insatisfatória } \\
& \text { - Indiferente } \\
& \text { - Muito satisfatória } \\
& \text { - Insatisfatória }
\end{aligned}
$$

Fonte: Dados da pesquisa (2018).

O quarto questionamento e seus desdobramentos evocam, sobretudo, a categoria "Representação Descritiva e Temática da Informação" ao tratar dos processos de classificação, catalogação e indexação, bem como do conhecimento dos bibliotecários acerca das políticas e demais produtos informacionais existentes no site do sistema de bibliotecas, por exemplo, a política de indexação, manual de catalogação. 
No geral, obtêm-se percepções variadas, visto que $6,1 \%$ do público pesquisado compreende a pergunta como algo inerente à sua prática profissional. De outra forma, 6,1\% demonstram adotar práticas complementares e específicas, mesmo que não estejam presentes nos manuais e políticas do sistema, enquanto que $88 \%$ responderam quais os processos de catalogação, indexação, sistemas de classificação são utilizados no SB/UFC, em conformidade com as políticas existentes, independente de atuarem ou não nesses processos.

Com relação aos processos de Organização e Representação da Informação no SB/UFC, utiliza-se como padrão de sistema de classificação a Classificação Decimal de Dewey e, em casos específicos como da biblioteca setorial da Faculdade de Direito, promove-se a integração da Classificação Decimal de Dewey e da Classificação Decimal de Direito.

Em relação ao quinto questionamento acerca do conhecimento sobre mediação, grande parte, $(66,7 \%)$, utiliza leituras próprias e leituras recomendadas, logo em seguida, $63,6 \%$ conhecem por meio de dicas de leituras de periódicos, sites, dentre outros. Convém enfatizar que o sistema de bibliotecas envia dois e-mails por mês com leituras recomendadas para todos os servidores, além da mediação da informação ser abordada e disseminada neste recurso virtual também.

De outra maneira, 45,5\% discute a temática em grupos de pesquisa da universidade e 6,1\% em grupos de extensão; em contrapartida, 6,1\% não conhece, $3 \%$ do público percebe uma associação entre mediação e representação descritiva e temática da informação, visto que responde ainda não trabalhar com processos técnicos, possivelmente pelo seu pouco tempo de instituição. Por outro lado, $3 \%$ afirma que ouviu falar sobre mediação durante um bate-papo informal com colegas. 


\section{Quadro 2 - Relato dos bibliotecários que ouviram falar sobre mediação da informação a partir da biblioteca que atuam ${ }^{4}$}

\begin{tabular}{|c|c|}
\hline \multicolumn{2}{|c|}{$\begin{array}{l}\text { Questão } 5.1 \text { - Em relação à questão } 5 \text {, caso tenha ouvido falar da mediação da informação a partir da própria biblioteca } \\
\text { que atua, discorra à respeito. }\end{array}$} \\
\hline $\begin{array}{l}\text { Bibliote cários } \\
\text { (B) }\end{array}$ & Súmula das respostas \\
\hline B7 & $\begin{array}{l}\text { É fundamental a importância da interação do bibliotecário com o usuário no processo de aquisição da } \\
\text { informação, sendo assim entendemos que o processo de Mediação da Informação se constitui pela } \\
\text { interação informação/bibliotecário/usuário. }\end{array}$ \\
\hline B9 & $\begin{array}{l}\text { Mediação da informação no contexto das unidades de informação é uma ação na qual o profissional da } \\
\text { informação se coloca como mediador do sistema de informação na tentativa de atender às demandas } \\
\text { informacionais do usuário que acessa o sistema. Mediar a informação na forma de diálogo com o usuário } \\
\text { para traduzir a sua necessidade de informação expressa na sua linguagem (natural) para a linguagem do } \\
\text { sistema. Isto é, a linguagem na qual estão codificados as diversas tipologias de suporte informacional }\end{array}$ \\
\hline B18 & $\begin{array}{l}\text { As atividades dentro da biblioteca que vão desde o Processamento técnico até o Serviço de Referência } \\
\text { em si, nos fazem lidar, diariamente, com a mediação da informação, tendo em vista a necessidade de } \\
\text { mediar/ proporcionar à comunidade acadêmica a disponibilização e o acesso, da melhor maneira possivel, } \\
\text { aos documentos, informaç̃es, serviços e produtos oferecidos pela biblioteca. }\end{array}$ \\
\hline B19 & $\begin{array}{l}\text { mediação da informação enquanto criação de meios e instrumentos que facilitem o uso da informação pelo } \\
\text { usuário. }\end{array}$ \\
\hline B26 & $\begin{array}{l}\text { A meu ver a mediação da informação se dar por meio da relação... Diálogo entre Bibliotecário e usuário, } \\
\text { isto é, trocas de informações entre ambos. }\end{array}$ \\
\hline $\mathrm{B} 27$ & $\begin{array}{l}\text { Embora não tenha ouvido falar com esta nomenclatura, acredito que muitas ações realizadas vão ao } \\
\text { encontro do que propõe a mediação da informação. }\end{array}$ \\
\hline
\end{tabular}

Fonte: Dados da pesquisa (2018).

No tocante ao conhecimento de mediação da informação a partir da biblioteca em que atua, elabora-se uma súmula das respostas coletadas, ou seja, de B7, B9, B18, B19, B26 e B27, obtidas no Quadro 2.

Diante disso, depreende-se que o público pesquisado observa a mediação da informação na ambiência da biblioteca como:

a) ação cotidiana do profissional da informação, presente desde o serviço de referência ao processamento técnico;

b) interlocução entre o bibliotecário e a comunidade de usuários e suas respectivas demandas, desejos e necessidades de informação - B7, B9, B26;

c) conceito e termo novo ainda, Almeida Júnior (2009) foi o pioneiro, estudioso da área, no entanto pode-se revelar como prática antiga

\footnotetext{
${ }^{4}$ Compreende o relato de todos os que responderam a questão acerca do conhecimento da
} mediação da informação a partir da biblioteca que atuam. 
realizada inconsciente ou conscientemente pelo profissional da informação, conforme a concepção de B27;

d) construção de ações que promovam o acesso e o uso da informação - B18, B19;

e) ação dialógica e interventiva promovida pelo bibliotecário no processo de tradução da linguagem do usuário para a linguagem do catálogo e demais recursos oferecidos pela biblioteca - B9.

Dessa forma, aliados ao que foi exposto acima sobre os conhecimentos acerca da mediação da informação, corroboram Tonello, Lunardelli e Almeida Júnior (2012); Silva (2015); Redigolo e Silva (2017); Dal'Evedove Tartarotti, Dal'Evedove e Fujita (2017).

\section{Quadro 3 - Eventos que ouviu falar sobre mediação da informação}

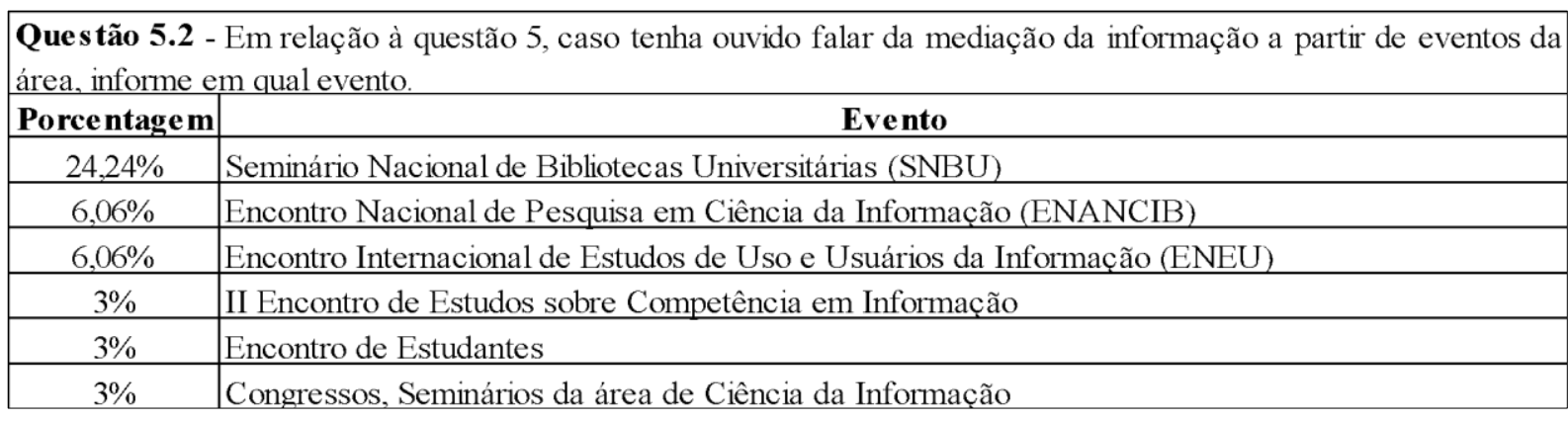

Fonte: Dados da pesquisa (2018).

No que tange aos eventos cujos respondentes ouviram falar sobre mediação da informação, observa-se como destaque o Seminário Nacional de Bibliotecas Universitárias (SNBU) com 24,24\%, conforme descrito no Quadro 3.

Diante disso, na visão dos sujeitos da pesquisa, as discussões em eventos decorrem da efervescência do SNBU como um evento especializado e exclusivo aos profissionais de $\mathrm{BU}$, inclusive o referido evento se constitui como consolidado e conclama a comunidade informacional para tratar especificamente das bibliotecas universitárias.

\section{Quadro 4 - Mídias sociais que ouviu falar sobre mediação da informação}

\begin{tabular}{|c|l|}
\hline $\begin{array}{l}\text { Questão } 5.3 \text { - Em relação à questão } 5 \text {, caso tenha ouvido falar da mediação da informação a partir } \\
\text { de mídias sociais, informe em qual(is) mídia(s) social(is). }\end{array}$ \\
\hline Porcentagem & \\
\hline $18,18 \%$ & Macebook \\
\hline
\end{tabular}




\begin{tabular}{|c|l|}
\hline $6,06 \%$ & Twitter \\
\hline $3 \%$ & Instagram \\
\hline $3 \%$ & Blogs \\
\hline $3 \%$ & Whatsapp \\
\hline $3 \%$ & Site INFOhome - OFAJ \\
\hline $3 \%$ & Site da Revista Biblioo \\
\hline
\end{tabular}

Fonte: Dados da pesquisa (2018).

Tratando-se do conhecimento sobre mediação da informação por meio de mídias sociais, 18,18\% informa o Facebook como o principal canal de comunicação, compartilhamento e disseminação de informações acerca da temática. Face ao exposto, observa-se uma constância nos resultados de uso do Facebook, tanto no questionário destinado à comunidade de usuários como nos estudos de Santos Neto e Almeida Júnior (2017) e, pelos internautas brasileiros (CONECTAÍ EXPRESS, 2017).

Neste sentido, é pertinente inserir nesta discussão a força das mídias sociais para estimular a leitura e a produção de conhecimentos, além de se constituírem como elementos fundamentais para pensar a mediação da informação.

\section{Gráfico 3 - Incentivos e parcerias que o SB/UFC estabelece para o desenvolvimento de ações mediadoras}

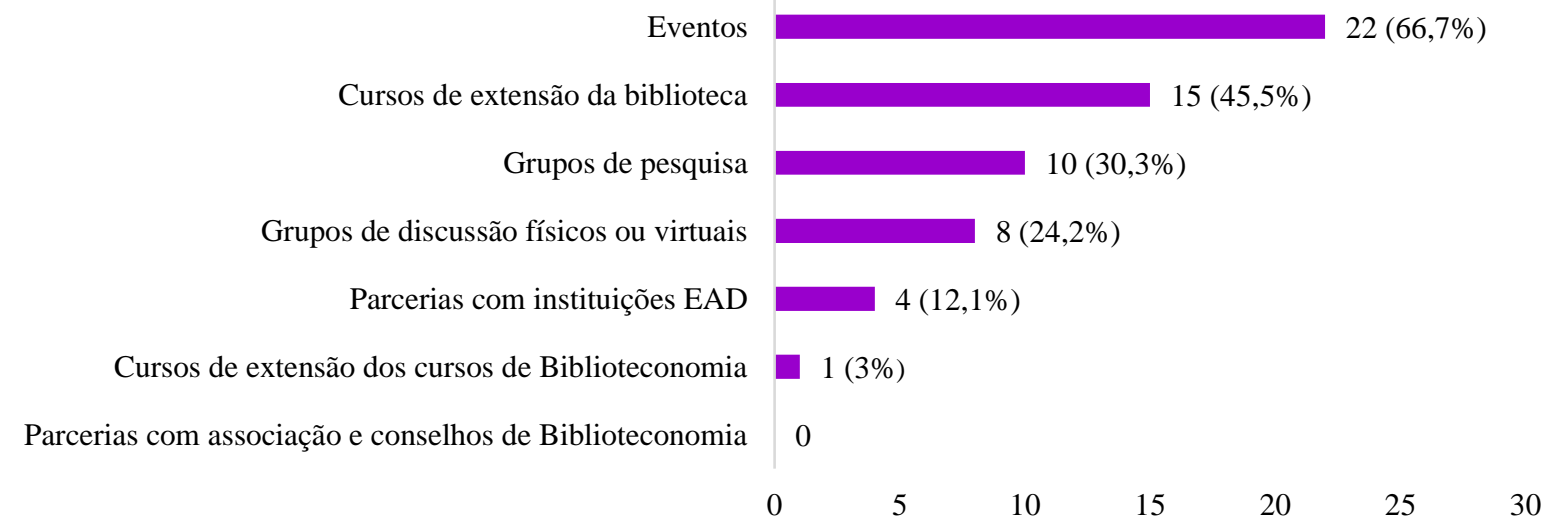

Fonte: Dados da pesquisa (2018).

Com relação ao sexto questionamento, acerca dos incentivos e parcerias que o SB/UFC estabelece para o desenvolvimento de ações mediadoras, têmse como destaque os eventos (66,7\%), possivelmente os de cunho temático, de 
acordo com os cursos atendidos pela biblioteca, exemplo: a "Semana Nacional de Ciência e Tecnologia" (SNCT); os desenvolvidos com o apoio de fornecedores de base de dados, sindicatos, dentre outros, como a "Maratona do Conhecimento"; os promovidos, sobretudo, com a parceria de professores da universidade, a "Semana de Metodologia e Produção Científica" (SMPC); os de ampla repercussão por meio da promoção de serviços de informação utilitária, que aproximem a biblioteca do cotidiano social, exemplo: "Outubro Rosa", "Setembro Amarelo", prestação de serviços de vacinação e doação de sangue, feiras agroecológicas e de economia solidária, dentre outros.

Observa-se ainda no Gráfico 3 que 45,5\% abordam os cursos de extensão da biblioteca como dinamizadores de ações mediadoras. Como exemplo no $\mathrm{SB} / \mathrm{UFC}$, identifica-se o curso de pesquisa escolar, integrado ao "Projeto de Extensão Literacia: competência informacional nas escolas".

Sob outra abordagem, porém ainda de caráter intrinsecamente extensivo, relata-se o projeto "Arte na Biblioteca", destinado à sociedade em geral e à comunidade acadêmica, atua na promoção de atividades artístico-culturais em uma das bibliotecas setoriais do SB/UFC, vinculado à Secretaria de Cultura Artística da Universidade Federal do Ceará (Secult-Arte/UFC), integra outros projetos e/ou ações, como cineclube, livros livres, livros prosa e arte, exposições, Semana Nacional de Ciência e Tecnologia, mostra artística.

Convém enfatizar outras ações extensionistas engendradas por meio de parcerias e incentivos relacionadas à saúde e bem-estar, segurança no trabalho, educação financeira, por exemplo: aulas de yoga, oficinas de culinária fitness, dentre outros.

Por conseguinte, $30,3 \%$ declaram 0 grupo de pesquisa como impulsionador de ações mediadoras. Depreendem-se como exemplo, os grupos "Competência e Mediação em ambientes de informação"; "Cultura, Mediação e Gestão da Informação", do Departamento de Ciências da Informação, da UFC.

De outra maneira, 24,2\% informam grupos de discussão físicos e virtuais como formas de incentivo e parcerias, aliado a isto, depreende-se alguns exemplos: Comissão Brasileira de Bibliotecas Universitárias (CBBU); Grupo de 
Estudos em Catalogação (GECAT), Comissões Especializadas de Estudo do SB/UFC, dentre outros.

$\mathrm{Na}$ verdade, parcerias e incentivos são concebidos geralmente sob a forma de programas, projetos, cursos, eventos e prestação de serviços. Estes, muitas vezes, atuam imbricados e geram múltiplas possibilidades de ações mediadoras.

Sendo assim, é possível perceber as concepções de Silva (2015) nas exposições acima. Em primeiro lugar, a mediação institucional presente nos procedimentos relacionados à captação de recursos internos e externos por meio da elaboração de programas, projetos, cursos, eventos e prestação de serviços para viabilizar ações e interferências e garantir a sustentabilidade destas ações.

Em segundo lugar, a mediação técnica nas ações de preservação do acervo, campanhas, grupos de discussão virtual e de pesquisa da universidade, comissões de estudo e, por último, porém não menos importante, a mediação pedagógica concretizada na oferta de treinamentos e cursos para promover a autonomia e a apropriação da informação pelo usuário.

\section{Gráfico 4 - Atividades da BU consideradas como elementos de atuação no âmbito da mediação da informação}

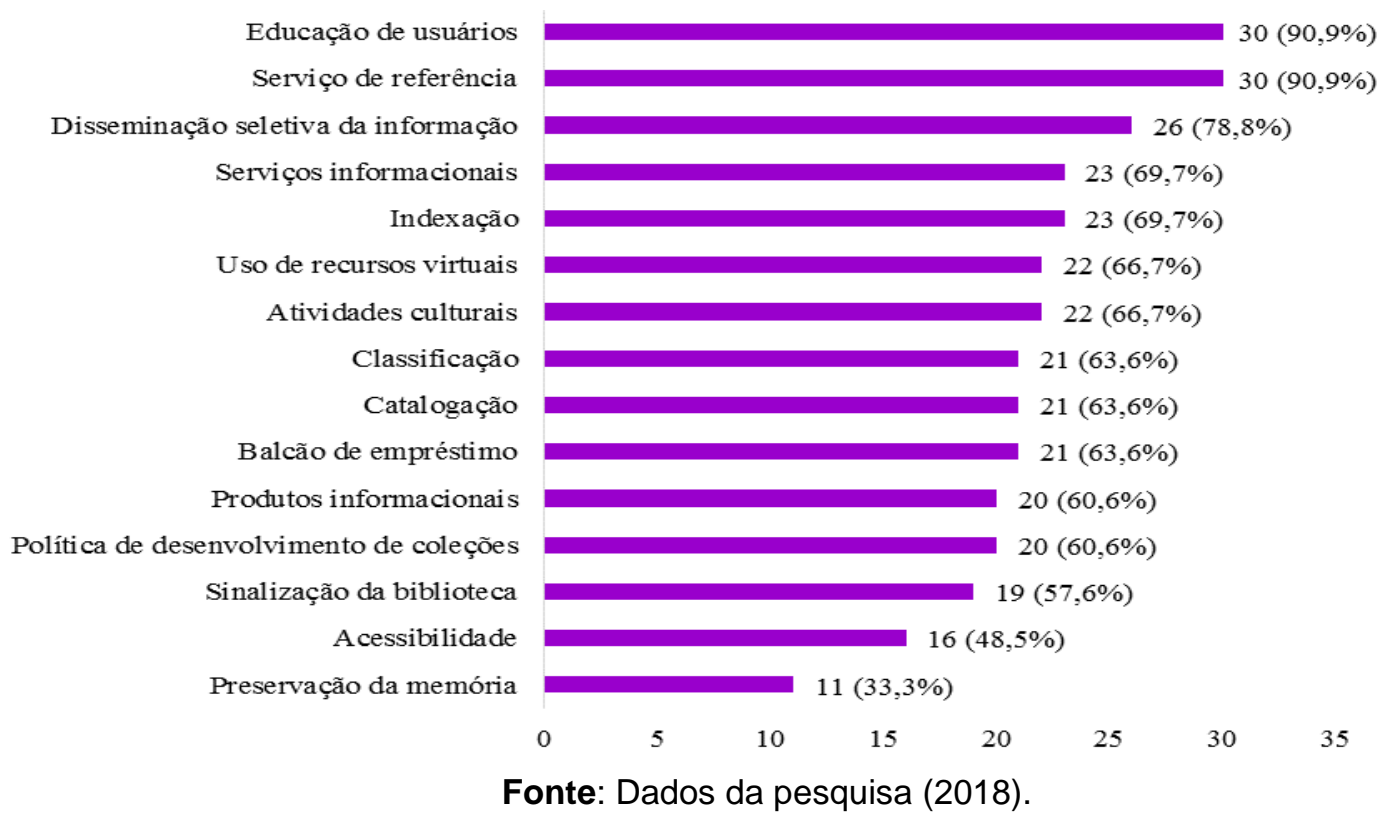

A sétima indagação, atividades da BU consideradas como elementos de atuação no âmbito da mediação da informação, evoca todas as categorias da 
análise de dados. Observa-se como destaque que 90,9\% dos respondentes identificam atividades mais voltadas à mediação pedagógica/ explícita, ou seja, serviço de referência e educação de usuários como elementos de atuação no âmbito da mediação da informação, conforme demonstra o Gráfico 4.

É pertinente destacar possíveis ações mediadoras que norteiam a educação de usuários, tais como: oficinas, treinamentos, eventos, prestação de serviços, fóruns/grupos de discussão, preconizadas por Silva (2016). Tais atividades atuam em várias temáticas relacionadas ao cotidiano da comunidade interna e externa da universidade, como exemplo, uso da biblioteca e de tudo que ela oferece, informação utilitária, cultura, dentre outros.

Diante disso, depreende-se que na visão do público pesquisado, tais atividades incidem mais fortemente no estabelecimento de práticas mediadoras, no entanto são impreteríveis as discussões sobre as múltiplas possibilidades da mediação da informação, interligadas como atividades holísticas, estratégicas e complementares, trazendo à baila o discurso arrazoado por Silva e Farias (2017) e Silva (2017) em que a mediação técnica, pedagógica e institucional devem atuar de maneira conjunta, promovendo práticas qualitativas para educação de usuários, serviço de referência, disseminação seletiva da informação etc.

Conquanto, ações mediadoras essencialmente de cunho pedagógico, como atividades culturais (66,7\%); balcão de empréstimo (63,6\%) são menos citados. Este último, possivelmente atrelado à ruptura da ideia reducionista da biblioteca como mero espaço de coleções e empréstimo de livros.

No que concerne à mediação técnica, identificam-se práticas mediadoras associadas inexoravelmente à Organização da Informação, como as de Representação Descritiva e Temática da Informação: indexação (69,7\%); classificação (63,6\%); catalogação (63,6\%).

Por outro lado, os serviços informacionais $(69,7 \%)$ e o uso de recursos virtuais $(66,7 \%)$, atividades antes não percebidas como perspectivas de aplicação da Organização da Informação no âmbito da mediação técnica, estão praticamente iguais ou um pouco à frente na frequência de respostas das práticas tradicionais relacionadas à Mediação e à Organização da Informação, 
tais como: indexação, classificação e catalogação.

\section{Gráfico 5 - Ações mediadoras que considera possível desenvolver a partir da Organização da Informação}

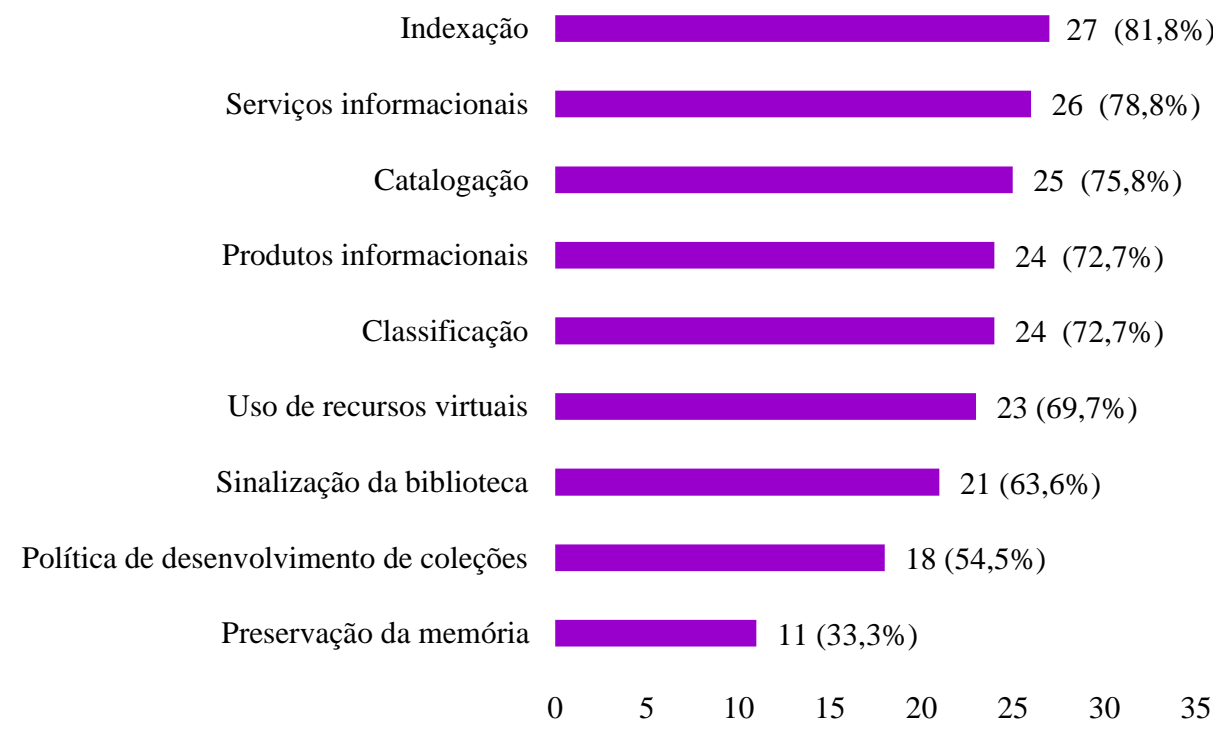

Fonte: Dados da pesquisa (2018).

O oitavo questionamento, ações mediadoras que considera possível desenvolver a partir da Organização da Informação, evoca de forma literal todas as categorias da análise de dados, exceto "Outros". Ao analisar as respostas obtidas, observa-se que $81,8 \%$ abordam a indexação como possível ação mediadora desenvolvida a partir da Organização da Informação, haja vista sua expressividade latente em estudos disponíveis sobre múltiplas possibilidades de aplicação da indexação como fenômeno de mediação, conforme explicitam Redigolo e Silva (2017); Dal'Evedove Tartarotti, Dal'Evedove, Fujita (2017); Tonello, Lunardelli e Almeida Júnior (2012).

Em termos de impacto, percebe-se em geral, uma variação equilibrada no tocante às ações mediadoras desenvolvidas a partir da Organização da Informação, conforme a avaliação do público pesquisado.

Por outro lado, há uma determinada unidade e consonância com as respostas da questão sete (atividades da BU consideradas como elementos de atuação no âmbito da mediação da informação), logo, serviços informacionais $(78,8 \%)$; produtos informacionais $(72,7 \%)$; uso de recursos virtuais $(69,7 \%)$, 
atividades pouco vislumbradas como perspectivas de aplicação da Organização da Informação no âmbito da mediação técnica, obtêm praticamente a mesma frequência de respostas das práticas consideradas tradicionalistas, atinentes à Mediação e à Organização da Informação, tais como: indexação, catalogação e classificação.

Em menor número, assim como na indagação sete (atividades da BU consideradas como elementos de atuação no âmbito da mediação da informação), figuram as práticas mediadoras: sinalização da biblioteca $(63,6 \%)$; política de desenvolvimento de coleções (54,5\%); preservação da memória $(33,3 \%)$. Destarte, é salutar a construção de propostas aplicativas da Organização da Informação no âmbito da mediação técnica que transcendam a visão tradicionalista dos processos.

\section{Gráfico 6 - Ações mediadoras que cada biblioteca desenvolve}

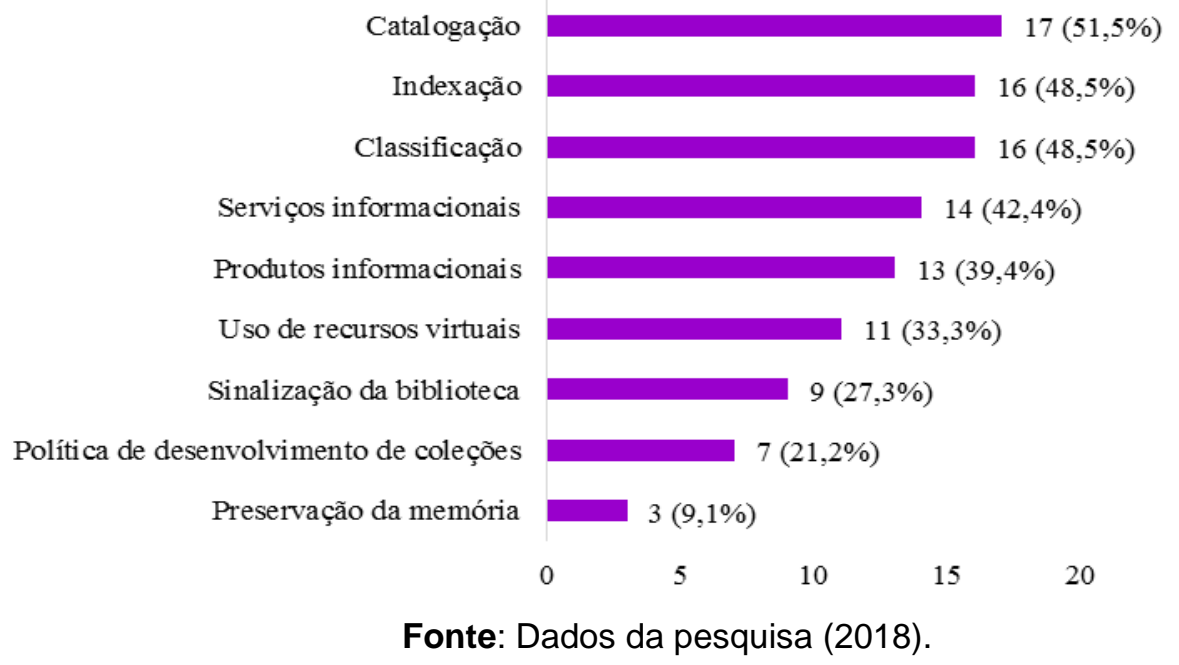

Com base nas opções marcadas na questão oito (ações mediadoras que considera possível desenvolver a partir da Organização da Informação), perguntam-se quais ações mediadoras cada biblioteca desenvolve (nono questionamento). Identifica-se que esta última evoca todas as categorias envidadas na análise de dados.

Com relação às ações mediadoras que o sistema de bibliotecas da UFC desenvolve, têm-se como destaque as ações mediadoras consideradas tradicionais: catalogação $(51,5 \%)$; indexação $(48,5 \%)$ e classificação $(48,5 \%)$. 
Por conseguinte, serviços e produtos informacionais representam $42,4 \%$ e $39,4 \%$ das respostas, respectivamente, o uso de recursos virtuais $(33,3 \%)$. Com isso, observa-se uma introdução a abordagens múltiplas no âmbito aplicativo da mediação técnica da informação.

No entanto, os respondentes formam uma espécie de padrão repetitivo, uma constante linearidade nas respostas das questões 7, 8 e 9, no que concerne às práticas mediadoras: sinalização da biblioteca (27,3\%); política de desenvolvimento de coleções $(21,2 \%)$; preservação da memória $(9,1 \%)$, pois elas figuram os últimos 3 lugares nas três indagações supracitadas.

Portanto, depreende-se a partir desta análise, a superação das abordagens tradicionalistas da mediação no âmbito da organização da informação, rumo à concepção de abordagens múltiplas em que a mediação no âmbito da organização da informação ganhe novos contornos e dinâmicas.

\section{Quadro 5 - Comentários, críticas e/ou sugestões sobre o questionário ${ }^{5}$}

\begin{tabular}{|c|c|}
\hline \multicolumn{2}{|r|}{ Comentários } \\
\hline B27 & $\begin{array}{l}\text { Acredito que o objetivo da pes quis a é muito relevante, bem como as perguntas estão claras e condizentes com } \\
\text { es te. }\end{array}$ \\
\hline B12 & Ques tionário no ponto, s em delongas e/ou perguntas demas iadas. \\
\hline B30 & $\begin{array}{l}\text { Assunto de muita relevância, como diz Almeida Júnior (2004) afirma que, "a razão de ser do bibliotecário se } \\
\text { encontra na mediação da informação". }\end{array}$ \\
\hline \multicolumn{2}{|r|}{ Críticas e/ou Suges tões } \\
\hline B19 & $\begin{array}{l}\text { Não entendi a parte Organização e Representação da Informação relacionada mais diretamente a mediação da } \\
\text { informação. }\end{array}$ \\
\hline B15 & $\begin{array}{l}\text { Acredito que o Sistema de Bibliotecas (SB) deve uniformizar algumas condutas relacionadas à mediação. Por } \\
\text { exemplo, o processo de indexação e a sinalização nas bibliotecas ainda não é algo padronizado e iss o, com } \\
\text { certeza, atrapalha o proces so de mediação. A política de desenvolvimento de acervos também poderia ser melhor } \\
\text { utilizada, pois observa-se que a participação da comunidade acadêmica na aplicação dela é incipiente. }\end{array}$ \\
\hline B35 & $\begin{array}{l}\text { Acreditamos que as práticas de mediação da informação devem permear todas as atividades da Biblioteca } \\
\text { Universitária... E, um pressupos to é que a organização da informação em seu process amento técnico: catalogação, } \\
\text { indexação, classificação deve estar relacionada sempre e diretamente aos seus usuários e interligada } \\
\text { simultaneamente com as outras atividades, sendo portanto uma base fundamental para o estabelecimento preciso } \\
\text { destas onde tudo precisa estar conciso e coerente. }\end{array}$ \\
\hline
\end{tabular}

Fonte: Dados da pesquisa (2018).

A partir do exposto no quadro 5 , identificam-se comentários gerais que relatam clareza, objetividade e consistência nas perguntas do questionário

\footnotetext{
${ }^{5}$ Comprende o relato de todos que responderam acerca dos comentários, críticas e/ou sugestões sobre o questionário.
} 
destinado aos bibliotecários do sistema de bibliotecas da UFC.

As sugestões elencadas no décimo questionamento (comentários, críticas e/ou sugestões sobre o questionário) reiteram a visão do público pesquisado, sobretudo diante das questões 7 a 9 que envolvem mais precisamente a mediação e a organização da informação, o que reforça a necessidade propositiva do programa de atuação da mediação técnica no âmbito da Organização da Informação sob a finalidade de propalar as múltiplas possibilidades da mediação técnica da informação, bem como alcançar uma maior representatividade, elucidação, especialmente à padronização destas temáticas.

A questão 10 evoca com mais evidência as categorias: política de desenvolvimento de coleções; representação descritiva e temática da informação; outros.

\section{CONSIDERAÇÕES FINAIS}

No tocante ao objetivo proposto para a pesquisa, à metodologia e aos dados analisados, depreende-se de um modo geral que os respondentes:

a) atuam mais fortemente com os processos de catalogação;

b) demonstram satisfação com o Sistema Pergamum no âmbito da Organização e Representação da Informação;

c) apresentam-se satisfeitos com a atuação do Sistema de Bibliotecas da UFC no âmbito da Organização da Informação;

d) mencionam os processos de catalogação, indexação, sistemas de classificação utilizados no SB/UFC, em conformidade com as políticas existentes, independente de atuarem ou não nesses processos;

e) utilizam leituras próprias e leituras recomendadas, em relação ao conhecimento sobre mediação;

f) com relação aos incentivos e parcerias que o SB/UFC estabelece para o desenvolvimento de ações mediadoras, têm-se como destaque os eventos; 
g) identificam como elementos de atuação no âmbito da mediação da informação, atividades mais voltadas à mediação pedagógica/ explícita;

h) abordam a indexação como possível prática de mediação desenvolvida a partir da Organização da Informação;

i) elencam ações mediadoras consideradas tradicionais: catalogação, indexação, classificação, com relação às práticas de mediação que o sistema de bibliotecas da UFC desenvolve;

j) relatam clareza, objetividade e consistência nas perguntas do questionário e reforçam a necessidade propositiva do programa de atuação da mediação técnica no âmbito da Organização da Informação.

Pelo exposto, conclui-se que é interessante comentar e alçar a ideia de que a mediação vislumbra um novo olhar para as práticas de Organização da Informação, haja vista pode ser pensada como instrumento participativo e didático para e com a comunidade e a partir dos seguintes aspectos: Representação Descritiva e Temática da Informação; Sinalização; Política de Desenvolvimento de Coleções; Serviços; Produtos; Preservação da memória; Uso de recursos virtuais. Além de reverberar entre os profissionais da área o caráter mediacional dos setores que envolvem a Organização da Informação na biblioteca universitária.

Por fim, sugerem-se temas a serem desenvolvidos a partir deste artigo, tais como: mediação técnica como prática de aproximação da comunidade de usuários; mediação técnica como recurso de aprimoramento da gestão da BU (acervos, pessoal, serviços, produtos etc.); mediação técnica em BU no âmbito das tecnologias digitais; novos conceitos e aplicabilidades em mediação da informação na BU.

\section{REFERÊNCIAS}

ALMEIDA JÚNIOR, Oswaldo Francisco de. Mediação da informação e múltiplas linguagens. Revista Tendências da Pesquisa Brasileira em Ciência da Informação, Brasília, v. 2, n. 1, p. 89-103, jan./dez. 2009. Disponível em: https://bit.ly/2R8PdFX. Acesso em: 30 nov. 2019. 
CONECTAí Express. WhatsApp é o app de rede social mais usado pelos internautas brasileiros. São Paulo: CONECTAí Express: IBOPE Conecta, 2017. Disponível em: http://ibopeconecta.com/whatsapp-e-o-app-de-redesocial-mais-usado-pelos-internautas-brasileiros/. Acesso em: 30 nov. 2019.

DAL'EVEDOVE TARTAROTTI, Roberta Cristina; DAL'EVEDOVE, Paula Regina; FUJITA, Mariangela Spotti Lopes. Avaliação da consistência da indexação em Bibliotecas Universitárias Federais da Região Nordeste do Brasil. Anales de Documentación, Múrcia, v. 20, n. 1, p. 1-19, 2017. Disponível em: https://goo.gl/Xm8zAa. Acesso em: 30 nov. 2019.

FARIAS, Maria Giovanna Guedes. Mediação e competência em informação: proposições para a construção de um perfil de bibliotecário protagonista. InCID: Revista de Ciência da Informação e Documentação, Ribeirão Preto, v. 6, n. 2, p. 106-125, set. 2015. Disponível em: www.revistas.usp.br/incid/article/view/101368. Acesso em: 29 nov. 2019.

FERNANDES, Joana D'Arc Páscoa Bezerra; DE SOUZA, Osvaldo. A contribuição do processamento técnico biblioteconômico para a acessibilidade informacional. Revista Ciencias de la Documentación, Santiago, v. 3, n. 4, p. 7-29, oct./dic. 2017. Disponível em: https://bit.ly/2LccoeQ. Acesso em: 29 nov. 2019.

GALEFFI, Agnese; BERTOLINI, María Violeta; BOTHMANN, Robert L.; ESCOLANO RODRÍGUEZ, Elena; MCGARRY, Dorothy. Declaração dos Princípios Internacionais de Catalogação. Tradução: Marcelo Votto Teixeira; Revisado por Jorge Moisés Kroll do Prado. Den Haag: IFLA, 2018. Título original: Statement of International Cataloguing Principles. Disponível em: https://www.ifla.org/files/assets/cataloguing/icp/icp_2016-pt.pdf. Acesso em: 31 out. 2019.

GOMES, Henriette Ferreira; SANTOS, Raquel do Rosário. Bibliotecas universitárias e a mediação da informação no ambiente virtual: informações, atividades e recursos de comunicação disponíveis em sites. In: ENCONTRO NACIONAL DE PESQUISA EM CIÉNCIA DA INFORMAÇÃO, 10., 2009, João Pessoa. Anais eletrônicos [...]. João Pessoa: UFPB, 2009. p. 1-18. Disponível em: http://bit.ly/2sPoXpB. Acesso em: 30 nov. 2019.

MOLINA, Letícia Gorri. Tecnologias de informação e comunicação para gestão da informação e do conhecimento: proposta de uma estrutura tecnológica aplicada aos portais corporativos. In: VALENTIM, Marta (org.). Gestão, mediação e uso da informação. São Paulo: Cultura Acadêmica, 2010. cap. 7. Disponível em: http://books.scielo.org/id/j4gkh/pdf/valentim9788579831171.pdf. Acesso em: 30 nov. 2019.

ORTEGA Y GASSET, José. Missão do bibliotecário. Brasília: Briquet de Lemos, 2006. 
REDIGOLO, Franciele Marques; SILVA, Marli Vitor da. A representação temática como mediadora implícita da informação em bibliotecas universitárias. Ponto de Acesso, Salvador, v. 11, n. 2, p. 49-69, ago. 2017. Disponível em: https://portalseer.ufba.br/index.php/revistaici/article/download/14307/15195. Acesso em: 29 nov. 2019.

SANTOS NETO, João Arlindo dos; ALMEIDA JÚNIOR, Oswaldo Francisco de. Bibliotecas universitárias das instituições estaduais de ensino superior paranaenses e a mediação da informação no facebook. Revista Digital de Biblioteconomia e Ciência da Informação, Campinas, v. 15, n. 2, p. 442-468, maio/ago. 2017. Disponível em:

https://periodicos.sbu.unicamp.br/ojs/index.php/rdbci/article/view/8648210/pdf. Acesso em: 29 nov. 2019.

SILVA, Jonathas Luiz Carvalho; SILVA, Andreia Santos Ribeiro. A mediação da informação como prática pedagógica no contexto da biblioteca escolar: algumas considerações. Biblioteca Escolar em Revista, Ribeirão Preto, v. 1, n. 2, p. 1-30, 2012. Disponível em:

http://www.revistas.usp.br/berev/article/view/106561/105158. Acesso em: 29 nov. 2019.

SILVA, Jonathas Luiz Carvalho; FARIAS, Maria Giovanna Guedes. Abordagens conceituais e aplicativas da mediação nos serviços de informação. InCID: Revista de Ciência da Informação e Documentação, Ribeirão Preto, v. 8, n. 2, p. 106-123, set. 2017. Disponível em: http://www.revistas.usp.br/incid/article/view/122628/133890. Acesso em: 28 nov. 2019.

SILVA, Jonathas Luiz Carvalho. Como a biblioteca universitária pode contribuir para as práticas de pesquisa? INFOhome, Marília, SP, p. [1-6], dez. 2016. Disponível em: https://www.ofaj.com.br/colunas_conteudo.php?cod=1022. Acesso em: 30 nov. 2019.

SILVA, Jonathas Luiz Carvalho. Percepções conceituais sobre mediação da informação. InCID: Revista de Ciência da Informação e Documentação, Ribeirão Preto, v. 6, n. 1, p. 93-108, mar./ago. 2015. Disponível em: http://www.revistas.usp.br/incid/article/view/89731. Acesso em: 10 jun. 2017.

SILVA, Jonathas Luiz Carvalho. Reunião de orientação. Fortaleza, 8 set. 2017. 1 áudio (56 min), extensão M4A (38,8 MB).

TONELLO, Izângela Maria Sansone; LUNARDELLI, Rosane Alvares; ALMEIDA JÚNIOR, Oswaldo Francisco de. Palavras-chave: possibilidades de mediação da informação. Ponto de Acesso, Salvador, v. 6, n. 2, 2012. Disponível em: https://goo.gl/KT5uEQ. Acesso em: 30 nov. 2019. 


\title{
RELATIONSHIP BETWEEN MEDIATION AND INFORMATION ORGANIZATION: APPLIED STUDY IN LIBRARY SYSTEM OF THE FEDERAL UNIVERSITY OF CEARÁ
}

\begin{abstract}
Introduction: This work discusses relational perspectives between Mediation and Information Organization under a plural and integrative perception of these research fields at the University Library environment. Objective: Investigating the relationship between mediation and information organization from the perceptions of librarians of the Federal University of Ceara. Methodology: The methodology consists of a descriptiveexploratory research, literature and documentary review of qualitative essence, in addition to the use of questionnaire and content analysis. Results: The questionnaire was answered by 33 librarians with the following profile: most of them act more strongly with cataloging processes; $76 \%$ are satisfied with the Pergamum System within the Organization and Information Representation; $82 \%$ are satisfied with the performance of the UFC Library System within the Information Organization; 88\% answered which processes of cataloging, indexing and system classification are used at SB/UFC in accordance with existing policies, regardless of whether or not they act in these processes. Regarding knowledge about mediation, $66.7 \%$ use their own readings and recommended readings; $66 \%$ report the events as a form of incentive and partnership for the development of mediation actions; $90.9 \%$ identify activities focused on pedagogical mediation, that are referral service and education of the user as elements of action in the field of information mediation; Regarding the mediation practices that the UFC library system develops, the most prominent are the mediating actions considered traditional: cataloging (51.5\%); indexation (48.5\%); rating (48.5\%). Conclusions: it can be concluded that the application of mediation in information organization can be thought from the following aspects: Descriptive and Thematic Representation of Information; Signaling; Collection Development Policy; Services; Products; Preservation of memory; Use of virtual resources. Even the union of the listed aspects above expresses a more holistic perception to rethink mediation from the perspective of information organization.
\end{abstract}

Descriptors: Information mediation. Technical mediation of information. Information organization. Academic libraries. Federal University of Ceará.

\section{RELACIONES ENTRE ORGANIZACIÓN Y MEDIACIÓN DE LA INFORMACIÓN: ESTUDIO APLICADO EN LA UNIVERSIDAD FEDERAL DEL CEARÁ}

\author{
RESUMEN \\ Introducción: Discute las perspectivas relacionales entre la Organización de Mediación
}


e Información bajo una percepción plural e integradora de estos campos de investigación en el ambiente de la biblioteca universitaria. Objetivo: investiga la relación entre la mediación y la organización de la información desde las percepciones de los bibliotecarios de la Universidad Federal de Ceará. Metodología: consiste en una investigación descriptiva-exploratoria, revisión de la literatura, documental, cualitativa, además del uso de cuestionarios y análisis del contenido. Resultados: se verifica que el cuestionario fue respondido por 33 bibliotecarios con el siguiente perfil: la mayoría de ellos actúa más fuertemente con los procesos de catalogación; 76\% están satisfechos con el Sistema Pergamum dentro de la Organización y Representación de la Información; el 82\% está satisfecho con el desempeño del Sistema de Bibliotecas UFC dentro de la Organización de la Información; el 88\% respondió que procesos de catalogación, indexación, sistemas de clasificación se utilizan en SB / UFC, de acuerdo con las políticas existentes, independientemente de actuar o no en estos procesos; con respecto al conocimiento sobre la mediación, el $66.7 \%$ usa sus propias lecturas y lecturas recomendadas; el $66 \%$ informa los eventos como una forma de incentivo y asociación para el desarrollo de acciones de mediación; el 90,9\% identifica actividades más centradas en la mediación pedagógica, es decir, el servicio de referencia y educación del usuario como elementos de acción en el campo de la mediación de la información; en cuanto a las prácticas de mediación que desarrolla el sistema de bibliotecas de UFC, las más destacadas son las acciones de mediación consideradas tradicionales: catalogación (51.5\%); indexación (48.5\%); calificación (48.5\%). Conclusiones: se puede concluir que la mediación en la Organización de la Información se puede considerar a partir de los siguientes aspectos: Representación descriptiva y temática de la información; Señalización; Política de desarrollo de colecciones; Servicios; Productos; Preservación de la memoria; Uso de recursos virtuales. Incluso la unión de los aspectos enumerados expresa una percepción más holística para repensar la mediación de la Organización de la Información.

Descriptores: Mediación de la información. Mediación técnica de la información. Organización de la información. Bibliotecas universitarias. Universidad Federal del Ceará.

Recebido em: 14.12 .2019

Acesso em: 26.05.2020 